\title{
CINEMA E EDUCAÇÃO AMBIENTAL NO PARQUE NACIONAL DA RESTINGA DE JURUBATIBA: REFLEXÕES E PRÁTICAS INTERDISCIPLINARES E TRANSVERSAIS*
}

\author{
Nathalia Moura Muzy Fuentes ${ }^{1}$ \\ Rafael Nogueira Costa ${ }^{1}$ \\ Christine Ruta ${ }^{1}$
}

\begin{abstract}
RESUMO: Este trabalho tem como objetivo principal analisar a produção de cinema-documentário no campo da educação ambiental (EA) crítica, no Parque Nacional da Restinga de Jurubatiba. No presente estudo, é apresentada a metodologia utilizada para produçáo de quatro documentários sobre o Parque Nacional, e a análise dos discursos dos personagens dos documentários. O Parque Nacional foi caracterizado pelos personagens dos documentários, pelas contradiçóes existentes na sua criação, implantação e gestão, pelos entraves existentes para o desenvolvimento local sustentável e pelos conflitos socioambientais. Os documentários demonstraram ser uma importante ferramenta pedagógica para a EA na criação de espaços para diálogos sobre as relaçóes existentes entre a sociedade e o meio ambiente.
\end{abstract}

Palavras-chave: Antropologia visual. Audiovisual. Ensino. Ecologia. Unidade de conservação.

\section{ENVIRONMENTAL CINEMA AND EDUCATION IN THE RESTINGA DE JURUBATIBA NATIONAL PARK: INTERDISCIPLINARY AND TRANSVERSAL REFLECTIONS AND PRACTICES}

ABSTRACT: This study aimed at analyzing the production of documentary filmmaking in critical environmental education (EE) in the Restinga de Jurubatiba National Park. The study presents the methodology used for the production of four documentaries about the National Park, and the analysis of the speeches of the documentaries' characters. The National Park was featured by the characters for the contradictions in its creation, implementation and management, the existing barriers to sustainable local development and the socio-environmental conflicts. The documentaries were shown to be an important educational tool for EE in the creation of dialogue spaces about the relationship between society and the environment.

Keywords: Visual anthropology. Audiovisual. Education. Ecology. Conservation unit.

\footnotetext{
*Esse artigo é resultado da pesquisa de mestrado, cuja dissertação é intitulada "Territórios, saberes e imagens: um estudo sobre a percepção da populaçâo do entorno sobre o Parque Nacional da Restinga de Jurubatiba, Rio de Janeiro, Brasil”, fomentado pelas agências CAPES, através da concessáo de bolsa de mestrado, e CNPq e FAPERJ, por meio de materiais utilizados para a realização da pesquisa.

${ }^{1}$ Universidade Federal do Rio de Janeiro - Rio de Janeiro (RJ), Brasil. E-mails: nathalia.fuentes@gmail.com, rafaelnogueiracosta@gmail.com, christineruta@gmail.com
}

DOI: 10.1590/ES0101-73302016160464 


\section{Cinéma et éducation environnementale dans le Parc NATIONAL DE LA RESTINGA DE JURUBATIBA: REFLEXIONS ET PRATIQUES INTERDISCIPLINAIRES ET TRANSVERSALES}

RESUMÉ: Cet article vise à analyser la production des films documentaires sur l'éducation relative à lenvironnement (ErE) socialement critique dans le Parc National de la Restinga de Jurubatiba. Dans cette étude, nous présentons la méthodologie utilisée pour produire quatre documentaires sur le Parc National, et l'analyse du discours des personnages aux documentaires. Le Parc National a été caractérisé par les personnages des documentaires par les contradictions existantes pendant sa création, implantation et gestion, par les entraves pour soutenir le développement local durable et par les conflits socio-environnementaux. Les documentaires se sont dégagés importantes outil pour l'ErE pour la création d'espaces pour dialoguer à propos des relations entre la société et l'environnement.

Mots-clés: Anthropologie visuelle. Audiovisuel. Enseignement. Écologie. Unité de conservation.

\section{Introdução}

$\mathrm{P}$

assados 14 anos da criação do Sistema Nacional de Unidades de Conservação (SNUC), a questão central da relação entre sociedade e natureza ainda requer reflexóes. Observa-se, no cenário atual, a proliferação de formas autoritárias na gestão das áreas protegidas, promovendo muitas vezes a "invisibilização" do outro nos discursos científicos e dos técnicos responsáveis pela gestão desses espaços (GERHARDT, 2007).

Neste sentido, a “educação ambiental na gestão participativa” é colocada como a responsável pela condução de um processo no mínimo mais democrático (LOUREIRO; CUNHA, 2008). Por outro lado, essa proposta muitas vezes não é incorporada de forma efetiva nos espaços decisórios, gerando conflitos e prejuízos, principalmente para aqueles cujos interesses são atingidos pelas decisóes "superiores". Com isso, observa-se ainda uma tendência na prática de uma educação voltada para o adestramento ambiental, uma espécie de adequação dos indivíduos ao sistema social vigente, priorizando os estudos técnicos ou naturais em detrimento das questóes sociais (BRUGGER, 1994).

Em contrapartida, o cinema e a produção de imagens ganham força na contemporaneidade, surgindo como uma ferramenta poderosa de socialização de informaçóes e podendo funcionar como fontes especiais de educação e construção de conhecimento (OLIVEIRA, 2006; FISCHER, 2009). Para Gutfreind (2006), o cinema como construção sociocultural pode ser compreendido como uma estrutura 
plural que engloba produção, consumo, hábitos, valores simbólicos e imaginários criativos. Em outras palavras, podemos dizer que o cinema funciona como um produto de base da sociedade contemporânea, participando da psiquê da comunidade, da consciência e da experiência dos indivíduos (GUTFREIND, 2006, p. 2).

Sem a pretensão de oferecer fórmulas metodológicas, pretendemos neste artigo - após a produção de quatro filmes realizados entre os anos de 2011 e 2013, em parceria com o curso de Graduação em Licenciatura em Ciências Biológicas e o Programa de Pós-Graduação em Ciências Ambientais e Conservação (PPG-CiAC), ambos da Universidade Federal do Rio de Janeiro (UFRJ), em Macaé - oferecer aos leitores reflexões sobre a nossa aproximação com o campo da antropologia visual. Foi somente a partir da experiência na construçáo de "filmes de encontro", nos quais aguçamos a nossa escuta com os grupos locais ou residentes de uma Unidade de Conservação (UC) de proteção integral, que ampliamos o nosso entendimento em relação às controvérsias presentes na gestão desses espaços (FUENTES et al., 2011; FUENTES, 2013; COSTA; YU-MING; SÁNCHEZ, 2015).

Espera-se neste artigo responder as questóes seguintes. A prática cinematográfica, quando produzida e utilizada dentro do universo acadêmico, pode ser uma ferramenta para ampliar a discussão dos problemas na gestão dos espaços protegidos? É possível, pela produçáo de filmes, conhecer as realidades locais e propor reflexóes sobre a gestáo destes espaços?

Essas questões foram respondidas com base na experiência proporcionada pela construçáo coletiva, realizada com personagens que apresentavam diferentes relaçóes com o território em questão, antes mesmo de este ser institucionalizado como um parque nacional.

\section{O cinema como "construção social"}

A facilidade em atingir o público, com base em uma linguagem acessível e global, tornou o cinema uma ferramenta para diversos fins, como pesquisas científicas, onde a câmera funcionava como instrumento para o registro objetivo a serviço da ciência positivista (DA-RIN, 2004, p. 143).

Segundo Kornis (1992, p. 240), o primeiro autor a considerar o filme como registro histórico foi o polonês Boleslas Matuszewski, que fazia parte da equipe dos irmãos Lumière. Matuszewski defendia o valor da imagem cinematográfica, que era por ele entendida como "testemunho do olhar verídico e infalível" (KORNIS, 1992, p. 240). Já os cineastas russos Dziga Vertov e Sergei Eisenstein, ao contrário do princípio de autenticidade do registro de Matuszewski, entendiam que o filme é uma construção, ou seja, o filme seria criado a partir de sua montagem, e não poderia ser visto como uma reprodução fiel da realidade (KORNIS, 1992, p. 240). 
Para Nichols (2005, p. 47), o cinema documentário representa uma determinada visão do mundo, uma visão com a qual talvez nunca tenhamos nos deparado antes, mesmo que os aspectos do mundo nela representados nos sejam familiares. Neste sentido, os filmes funcionam como objetos culturais e sociais (KORNIS, 1992, p. 241). No livro A técnica do cinema, escrito em 1926 pelo russo Vsevolod Pudovkin, observa-se uma premissa de base: "câmera e montagem organizam um olhar que é a cristalização de uma perspectiva ideológica, de uma valoração das coisas, de uma visão de mundo" (XAVIER, 1983, p. 20).

As tentativas de representaçóes da realidade em forma de filme passaram por diversas mudanças na maneira de serem pensadas e produzidas. Nesse sentido, Jean Rouch, a partir da produção de mais de 100 filmes, ampliou os modos e narrativas, incorporando procedimentos e questionamentos que inventavam "o outro como sujeito em de vez de objeto", extraindo e construindo "verdades" de "ficçôes" e vice-versa, produzindo uma espécie de "antropologia compartilhada" (GONÇALVES, 2008).

Essa polissemia do filme permitiu classificaçóes em subgêneros, conforme apontado por Nichols (2005, p. 135), que definiu os seis possíveis modos de representação em: poético, expositivo, observativo, participativo, reflexivo e performático. Entretanto, o autor sugere que todos os modos descritos possuem limitações passíveis de acontecer durante a produção do documentário. Nesse ínterim, as limitaçôes são contornadas, uma vez que esses modelos não são engessados e podem coexistir em uma mesma obra, afinal, "o documentário não é apenas um conjunto fixo de técnicas, não trata de apenas um conjunto de questôes, não apresenta apenas um conjunto de formas e estilos" (NICHOLS, 2005, p. 48).

Segundo Lins e Mesquita (2008, p. 7), o interesse revigorado pela prática do cinema documental pode ser constatado pela ampliação de editais públicos, aumento de filmes produzidos na última década, criação de festivais especialmente dedicados a essa temática e presença crescente de documentários independentes na televisão brasileira.

O cinema foi também pensado como possibilidade de utilização na forma de

um poderoso instrumento de educaçáo no mais amplo sentido da palavra", conforme desenvolvido por John Grierson, que criou "um sistema alternativo de distribuiçáo e exibição, composto de salas especiais, escolas, sindicatos, associaçóes e unidades móveis, fazendo parte da maior rede de cinema educativo na Inglaterra (DA-RIN, 2004, p. 63).

Para Oliveira (2006, p. 134), a vivacidade das imagens e sua reprodutibilidade facilitaram sua aceitação como pura representação da realidade, e isso possibilitou que cenas filmadas fossem rapidamente aceitas como provas mate- 
riais, testemunhos insuspeitos e até evidências científicas (OLIVEIRA, 2006, p. 134). Porém, muito além de instrumento científico, o cinema é um grande veículo de divulgação de ideias, fazendo parte de um processo longo, amplo e com inúmeras ramificaçóes.

\section{O cinema como ferramenta para a educação ambiental}

A compreensão tradicional das relaçóes entre a sociedade e a natureza desenvolvidas até o século XIX, vinculadas ao processo de produção capitalista, considerava o homem e a natureza como polos excludentes, tendo subjacente a concepção de uma natureza objeto, fonte ilimitada de recursos à disposição do homem (BERNARDES; FERREIRA, 2010, p. 17). Até então, acreditava-se que o crescimento econômico náo deveria ter limites e que desenvolvimento significava o domínio completo da natureza pelo homem. Entretanto, nas décadas de 1960 e 1970, percebeu-se que os recursos naturais são esgotáveis e que o crescimento sem limites começava a se revelar insustentável. "Neste contexto, emerge a necessidade de se elegerem novos valores e paradigmas capazes de romper a dicotomia homem/ natureza" (BERNARDES; FERREIRA, 2010, p. 17).

Para Leff (2010, p. 112), a questão ambiental surgiu como uma crise da civilização, questionando a racionalidade econômica e tecnológica dominante e gerando mudanças globais em sistemas socioambientais complexos que afetam as condiçóes de sustentabilidade do planeta, propondo a necessidade de internalizar as bases ecológicas e os princípios jurídicos e sociais para a gestão democrática dos recursos naturais.

Nesse cenário de transformaçóes responsáveis pelo surgimento da questão ambiental, também se inicia um processo histórico do qual emerge a ciência moderna. Segundo Leff (2010, p. 60), este processo deu lugar à "distinção das ciências", fracionando o conhecimento e compartimentalizando a realidade em campos disciplinares confinados, com o propósito de incrementar a eficácia do saber científico e a eficiência da cadeia tecnológica de produção. A partir dessa premissa, iniciou-se a busca por um método capaz de reintegrar esses conhecimentos dispersos num campo unificado do saber. Leff (2010) ainda aponta que a problemática ambiental na qual confluem processos naturais e sociais de diferentes ordens de materialidade não pode ser compreendida em sua complexidade, nem resolvida com eficácia, sem a integração de campos diversos do saber.

$\mathrm{Na}$ educação, as discussões relacionadas à temática ambiental emergiram de forma abrangente em meados da década de 1980, com a realização dos primeiros encontros nacionais e a atuação crescente das ONGs ambientalistas e dos movimentos sociais que incorporaram a temática em suas lutas (LOUREIRO, LAYRARGUES, CASTRO, 2002). Segundo Loureiro (2006, p. 1474), 
a educação ambiental integra propostas educativas oriundas de concepçóes teóricas e matrizes ideológicas distintas, sendo reconhecida publicamente no Brasil como de inegável relevância para a construçáo de uma perspectiva ambientalista de mundo e de sociedade.

Dessa forma, apesar de compreendermos que existem diferentes visóes e concepções de "educação ambiental" e que ainda perdure uma fragmentação dos "saberes científicos", é na mídia televisiva e no cinema que a população é "informada" sobre as questóes ambientais.

Assim, as discussóes sobre o cinema ambiental ganham força e desdobram-se na criação de espaços específicos para a divulgação das produçóes, como acervos de filmes, e de locais de legitimação, como festivais de cinema ambiental (GUIDO, BRUZZO, 2011, p. 58). Diversos festivais com a temática ambiental estão sendo realizados no Brasil e no mundo, como o Festival Internacional de Cinema e Vídeo Ambiental (FICA), criado em 1999, que é um dos mais importantes acontecimentos do calendário cinematográfico nacional.

Muitos documentários têm sido produzidos em UCs, que é a denominação dada pelo SNUC às áreas naturais passíveis de proteção ambiental devido às suas características especiais. No geral, esses filmes apresentam-se num formato institucional, produzidos especialmente para serem exibidos aos visitantes, para que eles conheçam a fauna e flora locais. Esses documentários são, em sua maioria, uma junção de imagens com explicações didático-científicas sobre a UC, como é o caso do documentário do Parque Nacional da Chapada dos Veadeiros (BA), produzido pela Fundação Fórmula Cultural, patrocinado pela Pioneer do Brasil e com apoio do Instituto Chico Mendes de Conservação da Biodiversidade (ICMBio) e do Ministério da Cultura por intermédio da Lei Rouanet ${ }^{1}$.

Outros filmes também foram produzidos em UCs no Brasil. Podem ser citados os filmes Expedição Floriano (SPORKENS, 2004), Filhos de Jaú (ANDRADE, 2009) e Dança do Tempo (SPENCER, 2011). O filme Expedição Floriano conta a história da viagem de um grupo de pesquisa e fiscalização ao rio Floriano, no coração do Parque Nacional do Iguaçu (PR), em março de 2004. O filme Dança do Tempo apresenta de forma poética os elementos do Parque Nacional do Itatiaia (RJ), apresentando os ritmos e os padróes do Parque Nacional, trazendo a metáfora de que as movimentaçóes dinâmicas do ambiente compóem uma dança. E o filme Filhos de Jaú mostra o contraste entre a população amazonense que habita o Parque Nacional do Jaú (AM e RR) e os pesquisadores do Igapó Study Project, que pesquisam o sistema ecológico amazônico deste Parque Nacional.

Como apresentado acima, a produção de filmes vem sendo utilizada como estratégia de informação sobre a existência e importância das UCs para a 
população. Entretanto, são poucos os filmes que buscam explicitar as contradições socioambientais, que emergem após a criação desses espaços. Além disso, é possível pensar em um modelo para a educação ambiental a partir da utilização dessa estratégia, uma vez que não só o produto final, como o próprio processo de produçâo do documentário, pode servir como aprendizado sobre determinado tema.

\section{O Parque Nacional da Restinga de Jurubatiba}

A área de estudo deste artigo concentra-se no entorno do Parque Nacional da Restinga de Jurubatiba, localizado no litoral norte do Estado do Rio de Janeiro, nos municípios de Macaé, Carapebus e Quissamã. O Parque Nacional da Restinga de Jurubatiba é o único parque nacional de restinga do Brasil e abriga uma das áreas deste ecossistema mais preservadas do país. A criaçáo desta UC foi de grande relevância por garantir a efetiva conservação ao maior remanescente de restinga do Estado do Rio de Janeiro, incluindo seus diversos tipos de habitat, sua diversidade biológica e suas espécies endêmicas (ROCHA; ESTEVES; SCARANO, 2004).

O Parque Nacional da Restinga de Jurubatiba tem como objetivo a conservação desse ecossistema natural, de modo a possibilitar a realização de pesquisas científicas e o desenvolvimento de atividades de educaçáo ambiental e de turismo ecológico. Por estar situado na regiáo litorânea, o Parque está sob intensa pressão da ocupação humana, da forte especulação imobiliária relacionada ao litoral e consequente alteração da paisagem original. Além disso, a UC está situada na Bacia de Campos, a bacia sedimentar brasileira mais produtiva em exploração de petróleo, o que nesses últimos 20 anos ocasionou um intenso e desorganizado desenvolvimento demográfico.

\section{Curso de Cinema Ambiental (CUCA): participação e interdisciplinaridade}

O CUCA ${ }^{2}$ foi implantado no ano de 2011 na UFRJ, no campus de Macaé. A proposta do curso é promover a produção de documentários, funcionando como espaço para trocas entre os cursistas, os protagonistas e os alunos dos cursos de Licenciatura em Ciências Biológicas e Pós-Graduação em Ciências Ambientais e Conservação. Desta forma, são desenvolvidos documentários produzidos de maneira colaborativa. Ao registrar as histórias de vida de diferentes pessoas e suas relaçóes com a área onde foi criado o Parque Nacional da Restinga de Jurubatiba, busca-se valorizar o conhecimento dos grupos locais, ampliando o conhecimento da UC.

Os personagens são escolhidos nos três municípios que comportam o Parque Nacional e para cada um dos personagens é pensado um curso, gerando 
um documentário como resultado final, onde as histórias individuais se confundem com a história da criação da UC.

O curso é pautado em uma sequência que fornece uma aproximação entre o que é comentado pelo personagem e o que é construído pela equipe. A etapa 1 do trabalho se inicia a partir de uma seleção do personagem da comunidade que será o protagonista do filme, utilizando o método da Bola de Neve (BERNARD, 1988).

Nesta etapa, também é feita a seleção da equipe de colaboradores que vai desenvolver o filme. A seleção foi realizada após chamada pública, por meio de edital aberto para a comunidade. Buscou-se nesta seleção a formação de uma equipe com diferentes trajetórias, de forma a potencializar as trocas entre os participantes, favorecendo um olhar interdisciplinar na elaboração do filme.

$\mathrm{Na}$ etapa 2, pela escuta sensível, um tipo de escuta segundo a "abordagem transversal" (BERNARD, 1988), e com base em exercícios criativos, foram aparecendo as múltiplas possibilidades para a linguagem do filme. Já na etapa 3, a subjetividade é assumida e inicia-se a captação do material audiovisual, envolvendo diversas escolhas, como locação das filmagens, enquadramentos, gravaçóes de áudio e vídeo e, por fim, a montagem. Após esta etapa, uma versão do filme é apresentada para diferentes grupos, gerando um estudo de recepção para possíveis correçóes.

Por fim, na etapa 4, após a aprovação e aceitação do material produzido pelo protagonista, o filme pode ser considerado finalizado. Nesta última etapa, é esperado que a construção coletiva faça significado para o personagem registrado.

Os equipamentos utilizados nas filmagens do CUCA foram: câmera digital Canon EOS 60D, jogo de lentes $24-70 \mathrm{mmL}, 50 \mathrm{mmL}$ e $100 \mathrm{mmMA}$ $\mathrm{CRO}$, microfone lapela Sony e microfone direcional. Os filmes são editados com o software FinalCut Pro $7^{3}$.

\section{Areia de Quissamã (a luta pela preservação ambiental e memória histórica de um município)}

O documentário Areia de Quissamã conta a história de Dona Leninha (Figura 1), cidadã de Quissamã e ativista pela memória e natureza da sua cidade. Dona Leninha é também membro do conselho consultivo do Parque Nacional da Restinga de Jurubatiba. A maior parte do filme foi realizada em sua casa, transformada, em 1997, no Espaço Cultural José Carlos de Barcellos, criado com o propósito de resgatar a história local. Nesse espaço é possível consultar um acervo documental, como mapas, documentos, fotografias e reportagens que remontam à história de Quissamã. 


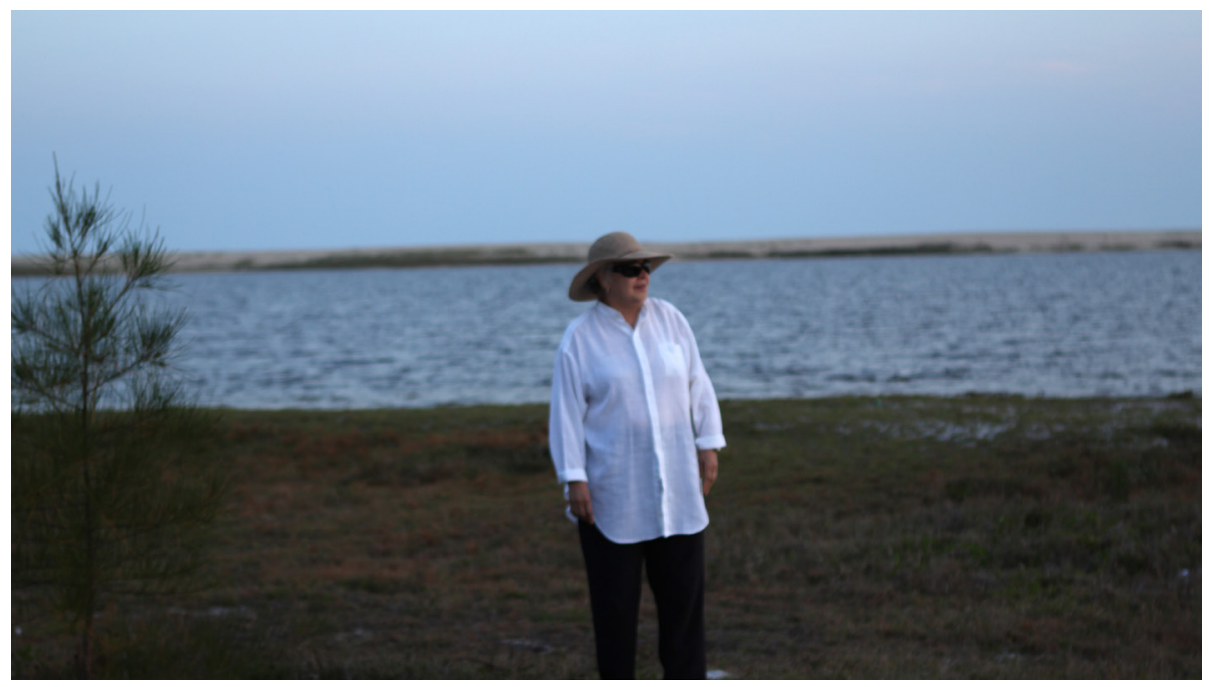

Figura 1

Dona Leninha. Cena do filme Areia de Quissamá.

No filme, Dona Leninha conduz o espectador por sua história de vida, que se mescla com a do município e, consequentemente, com a história do Parque.

Sua relação com a área onde foi criado o Parque surge na infância, quando brincava na "areia", forma pela qual a restinga era chamada pelas crianças. No filme, ela conta também a história do Engenho Central de Quissamã, apontado como o grande centro econômico do município e uma das primeiras iniciativas a causar a destruição da vegetaçáo de restinga. Ela explica que a lenha que alimentava as caldeiras da usina era retirada da restinga, mais especificamente de um local chamado de "rasgo". A retirada de madeira para a usina foi uma das atividades causadoras de alteraçôes ambientais nesta área, assim como o crescimento de atividades agropecuárias e construção de casas.

Dona Leninha também leva o espectador ao quintal da sua casa, mostrando que mantém a vegetaçáo natural de restinga intocada na parte não construída do seu terreno. A preservaçáo daquele pedaço é motivo de orgulho para ela, que afirma:

Se eu tivesse feito disso aqui um campo de futebol pros meus netos, pros meus filhos, e aí, a preservação? Fica como? Que moral eu teria? Como defender a restinga sem preservá-la? Eu tenho que dar o exemplo (transcrição de trecho do filme Areia de Quissamã).

Ela também comenta sobre os exemplares da flora que cultiva em seu quintal: 
Nós temos o cuité, ou cuitê, que tira para fazer o berimbau. A almécega (...) surge uma cera. Essa cera, no século XIX, aproveitava-se para sachê, pra perfumar a roupa, para o incenso, na igreja tem um incenso feito com a cera da almécega. Então são coisas assim... restinga pra mim é um negócio meio difícil, é apaixonante (transcriçáo de trecho do filme Areia de Quissamã).

No Areia de Quissamá, podemos observar a ausência de projetos das instituições locais visando à preservação do patrimônio histórico-cultural da região que deu origem ao Parque. Fica explicitada, no filme, a luta de uma mulher pela preservação da história local. Conclui-se que é justamente essa ausência de informaçóes um dos motivos que levam à não valorização da UC pelos moradores locais.

\section{Jorge Poema (pelo direito de pescar)}

O documentário Jorge Poema conta a história de Tio Jorge (Figura 2). Pescador, poeta e ex-presidente da Associação de Pescadores Artesanais da Lagoa de Carapebus, Tio Jorge é detentor de relevante conhecimento sobre a região que deu origem ao Parque Nacional da Restinga de Jurubatiba.

No filme, Tio Jorge conta sua história desde a infância, quando brincava e ajudava no sustento de sua família. Logo no início, ele explica de onde surgiu sua inspiração para se tornar poeta e sua vontade de divulgar o "seu povo" e as histórias de sua região.

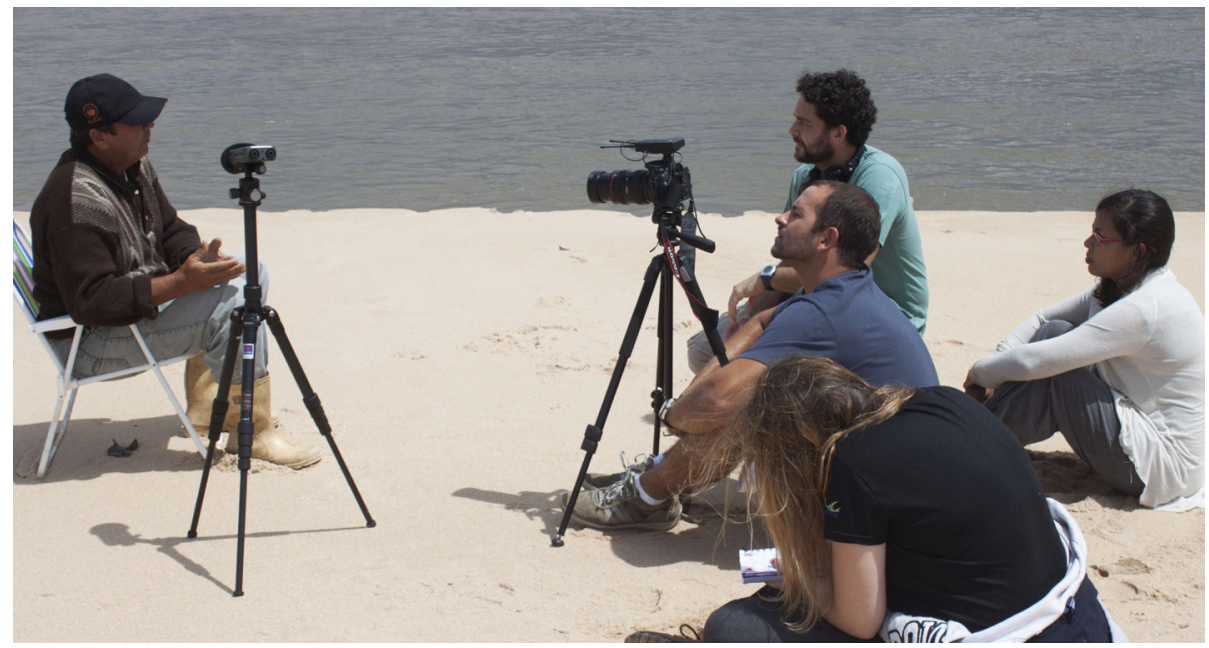

Figura 2

Tio Jorge em cena do filme Jorge Poema (Frame do filme Jorge Poema). 
Toda pessoa que nascia na nossa comunidade, a maioria deles, se arriscava nesse negócio de elogiar alguém. (...) E esse pessoal fazia aquele grupo, aqueles mais habilidosos saiam cantando, mas as crianças só podiam olhar de longe. Mas eu percebia "eu acho que também faço um verso desse”, mas ninguém vai dar conversa a criança, rapaz. (...) E eu comecei a ver que a nossa vida começou a mudar, nossa natureza começou a ser destruída, alteraçóes. Eu imaginei que se eu fizesse alguns versos focados naquilo que eu conheço, eu só fiz a rima. Eu peguei a história que tava acontecendo e passei a rima (transcrição de trecho do filme Jorge Poema).

A partir daí, Tio Jorge começou a compor diversos poemas, principalmente sobre sua infância e sobre a regiáo em que nasceu. Segundo ele, os poemas serviram para divulgar as agressóes à natureza, dando vida aos conflitos com os pescadores locais.

Ele também critica a limitada consideração das necessidades do pescador em todo o processo de gestão e implementação do Parque. Em um trecho do filme, apresenta uma foto da lagoa de Carapebus, feita há 30 anos, e a compara com a lagoa atual, explicando:

(...) o pescador artesanal de raiz, ele não depreda o meio ambiente, ele não destrói, ele preserva. $\mathrm{O}$ pescador não pode ser assim, arrancado daqui como uma pranta (sic) daninha. O pescador tem que se adequar (...) e continuar exercendo sua profissão ainda aqui dentro do Parque (transcrição de trecho do filme Jorge Poema).

De acordo com Santos (2008, p. 49), a lei que instituiu o SNUC (Lei $\mathrm{n}^{\circ}$ 9.985/00) estabeleceu que a categoria de parque nacional enquanto UC do grupo de proteção integral se destinaria apenas à manutenção dos ecossistemas livres de alteraçóes causadas por interferência humana, admitido apenas o uso indireto dos seus atributos naturais. Dessa forma, segundo Vainer (2010, p. 149), os pescadores que por décadas e geraçóes desenvolveram a atividade pesqueira na lagoa de Carapebus foram proibidos de exercer esta atividade, tradicionalmente associada à subsistência deste grupo, que é considerado pelo Plano de Manejo como uma comunidade tradicional.

Entretanto, apenas metade da lagoa de Carapebus está dentro dos limites do Parque Nacional da Restinga de Jurubatiba, o que acabou criando uma situação, no mínimo, curiosa, como descreve Vainer (2010, p. 150): após a criação da UC, a pesca ficou permitida em apenas parte da lagoa de Carapebus, localizada fora do Parque Nacional, enquanto em seu restante, ficou estritamente vedada pelo IBAMA, hoje ICMBio, até que fosse elaborado o Plano de Manejo. Entretanto, a demora na elaboração desse documento técnico provocou o abandono da pesca por parte dos pescadores e empurrou outros para a ilegalidade. 
Resta dizer que o Parque tem 18 lagoas costeiras e foi proibido para o pescador, comunidade tradicional, a pesca em 17 lagoas e meia. Sobrou apenas meia lagoa pro pescador. Eu não sou bom em matemática, que eu sou pescador. 18 , só sobrar meia lagoa? É uma conta meia (sic) desproporcional aí, mas em todo caso eu náo sei porque eu sou pescador, não sou matemático (transcrição de trecho do filme Jorge Poema).

Um dos maiores problemas causados por essa proibição foi o fato de que muitos pescadores obtinham o complemento da renda para o sustento de suas famílias da pesca nestas lagoas. Entretanto, além de inviabilizar uma prática rentável, a implementação do Parque Nacional nega aos pescadores a existência e a reprodução de sua tradição (FARJALLA; BOZELLI; LOUREIRO, 2011, p. 466).

Devido a isso, os pescadores passaram a se manifestar por meio da Associação de Pescadores Artesanais de Carapebus, criada em 1999, para tentar garantir sua participação na gestão do Parque. Segundo Farjalla, Bozelli e Loureiro (2011, p. 465), “o grupo passou a 'ocupar' o espaço público democrático por meio de suas reivindicaçóes políticas, referentes aos seus interesses e aos de sua representação nos processos decisórios”.

Foi apenas com a publicação do Plano de Manejo da Unidade, em 2008, que uma solução parcial foi apresentada para o problema. De acordo com o documento,

está proibida a pesca em todas as lagoas do Parque, exceto na lagoa de Carapebus, por parte dos pescadores tradicionais locais, enquanto não entre em vigor o TAC [Termo de Ajustamento de Conduta] a ser implantado pelo ICMBio e a Promotoria Pública (BRASIL, 2008).

Esse Termo de Ajustamento de Conduta (TAC) deveria ser firmado entre a Diretoria de UC de Proteção Integral do ICMBio (DIREP) e o Ministério Público Federal (MPF) para "prever o prazo para o encerramento das atividades de pesca dentro do Parque" e "levar em consideração os projetos a serem desenvolvidos para o ordenamento pesqueiro da Lagoa de Carapebus" (BRASIL, 2008). Entretanto, Santos (2008) e Vainer (2010) criticam essa determinação, já que o instrumento mais adequado ao caso seria o Termo de Compromisso previsto no SNUC. Como não se poderia considerar como crime a pesca artesanal dos pescadores tradicionais na lagoa de Carapebus, em função da previsão de regulamentação da mesma, afirma que não haveria sentido em se estabelecer um TAC que se presta a estabelecer ajustamentos após o cometimento de crime.

Independentemente dessa discussão jurídica, Vainer (2010) aponta que o Plano de Manejo prevê que apenas os pescadores reconhecidos como tradicionais sejam elegíveis para obtenção da licença de pesca. Dessa forma, seria 
necessária a comprovaçáo da tradicionalidade por parte dos pescadores, que deveriam apresentar documentos e testemunhas que atestassem suas atividades de pesca como principal fonte de renda antes de 1998, ano de criação do Parque Nacional. O TAC foi assinado no dia 17 de novembro de 2010 pelo MPF, em Macaé, e fixa algumas regras para os pescadores exercerem a atividade no Parque, como o horário de trabalho (das $17 \mathrm{~h}$ às $9 \mathrm{~h}$ ) e os pontos de partida dos barcos. Além disso, o TAC identifica os pescadores tradicionais pelo material de pesca, roupas e cor dos barcos, que não podem ser motorizados. $\mathrm{O}$ pescador que descumprir essas regras corre o risco de ser multado (dados retirados do website do $\mathrm{MPF}^{4}$ ). Segundo dados do website do ICMBio ${ }^{5}$, atualmente, 25 famílias de pescadores conseguiram autorização e continuam pescando na lagoa de Carapebus.

\section{Retira-te (entre o direito de propriedade e a preservação ambiental)}

O filme Retira-te conta a história do Sr. Satiro (Figura 3), um empresário de Sáo José dos Campos (SP) que, por meio de um plano de incentivo agrícola criado pelo governo do entáo presidente Fernando Henrique Cardoso, teve a oportunidade de, junto com outros amigos, se tornar dono de terras na regiáo Norte Fluminense, próximas ao município de Carapebus. A Fazenda Retiro seria utilizada para o cultivo extensivo de coco, o que, segundo o protagonista, geraria emprego e renda para a regiáo.

Ele conta que a perspectiva da realização de um projeto de fruticultura era interessante para a economia do município de Carapebus e que a mão-de-o-

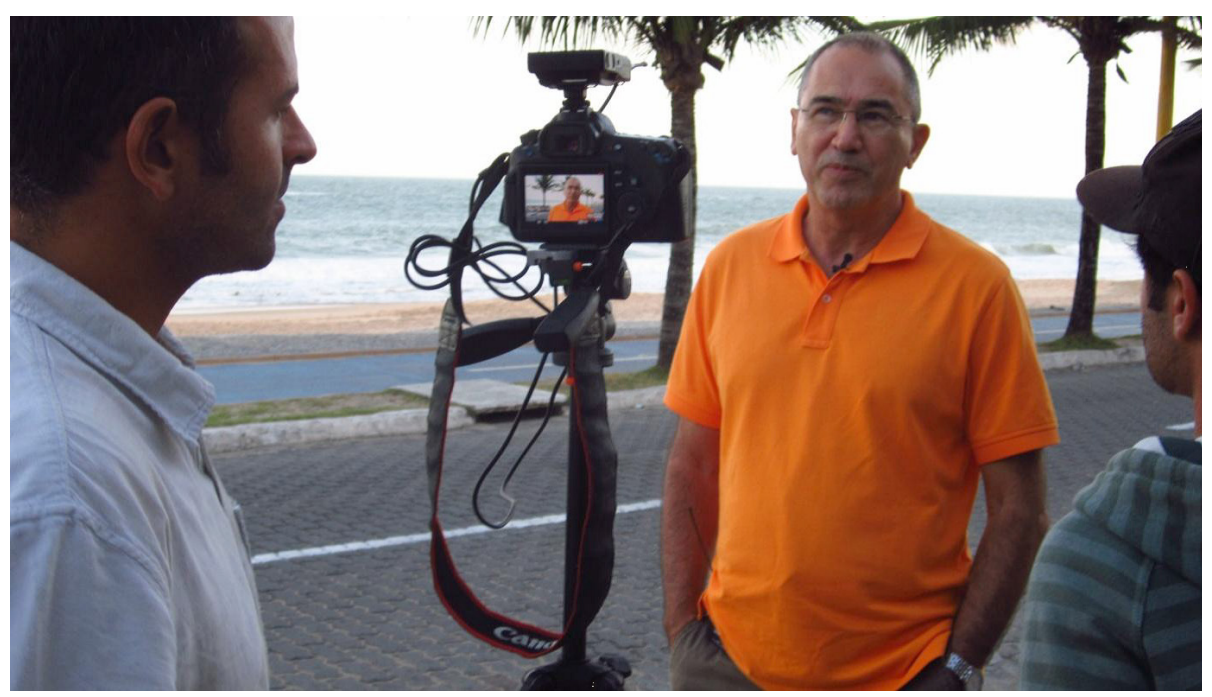

Figura 3

Sr. Satiro durante gravação do filme Retira-te. 
bra contratada foi inteira da região. Segundo Satiro, a vegetação nativa não foi retirada, e apenas os "espaços vazios" foram utilizados para o cultivo de coco. Além disso, ele explica que a expectativa de lucro era bastante animadora, o que os incentivou a investir no agronegócio.

Entretanto, pouco tempo depois da compra da fazenda, com a criação do Parque Nacional da Restinga de Jurubatiba, iniciou-se uma disputa judicial entre o Sr. Satiro e os advogados da Uniáo, por conta do valor legal de ressarcimento das terras, que foram incondicionalmente incorporadas ao Parque Nacional, um problema enfrentado na gestão de diversas áreas protegidas.

Apesar dos problemas que o Sr. Satiro enfrenta com os processos de regulamentação fundiária do Parque Nacional de Jurubatiba, ele é enfático ao afirmar que a existência dessa UC é, sim, importante, e afirma que foi favorável à criação do Parque Nacional, sendo inclusive um apoiador da iniciativa, mas sente-se triste, pois a sua relação afetiva com o lugar data da época em que ele frequentava a Fazenda Retiro.

\begin{abstract}
Algumas vezes eu vinha pra cá, chegava de manhã cedo, umas sete horas da manhã, depois de ter viajado a noite toda, ia pra fazenda, olhava, cuidava de tudo e voltava às quatro horas da tarde, chegava meia noite em casa. Porque era um sonho, né? (transcrição de trecho do filme Retira-te).
\end{abstract}

Essa luta por terras, conflito simbolizado pela questão apontada no filme, é uma metáfora dos muitos casos que o ICMBio, autarquia federal dotada de personalidade jurídica de direito público, autonomia administrativa e financeira, vinculada ao MMA, ainda tenta resolver em diversas UC.

\title{
Um Dia Novinho em Folha (o audiovisual como ferramenta de ensino)
}

Um Dia Novinho em Folha conta a história de IBR, um professor de Educação Artística da Prefeitura de Macaé que conduz em sua casa, no Lagomar, um projeto de educação voltado para as crianças do bairro. O objetivo do projeto, intitulado Projeto 127, é ensinar artes visuais - desenho, fotografia, cinema, entre outros - com a utilização de elementos da região, em especial o Parque Nacional da Restinga de Jurubatiba.

O professor IBR é também desenhista e cineasta amador, já tendo produzido cerca de dez filmes, todos no ambiente da restinga. Os filmes são histórias de ficção, em sua maioria longa-metragens. $\mathrm{O}$ roteiro, produção, filmagem e edição são realizados pelo próprio IBR, que convida os moradores do bairro para atuarem. 
Durante o filme Um dia novinho em folha, é possível vê-lo em atuação, chamando as crianças do bairro para a participação em mais um trabalho. Durante as filmagens, ele convida algumas crianças (Figura 4) que brincavam em frente às suas casas para fazer um filme, e o interesse é imediato. Neste ponto, a câmera do CUCA observa a forma espontânea como a história se desenrola, e, para o espectador, a "ficção" se confunde com o "real".

Este interesse pode ser observado entre os alunos do Projeto 127, um espaço de ensino não formal que se utiliza de ferramentas audiovisuais para o ensino. Essas ferramentas são todo e qualquer recurso que contenha som e imagem e seja utilizado para estimular o aluno, com o objetivo final de aprimoramento do processo ensino-aprendizagem. Segundo Rosa (2000, p. 39), "um filme ou um programa multimídia têm um forte apelo emocional e, por isso, motivam a aprendizagem dos conteúdos apresentados pelo professor".

Moran (2000, p. 32) defende que é possível e até necessário modificar a forma de ensinar e aprender, até porque ambas "exigem hoje muito mais flexibilidade espaço-temporal, pessoal e de grupo, menos conteúdos fixos e processos mais abertos de pesquisa e de comunicação". O professor IBR consegue, de forma prática e eficiente, manter o interesse dos alunos em temas relacionados ao ambiente e à arte, baseando-se em conhecimentos provenientes de suas próprias observaçóes do Parque Nacional da Restinga de Jurubatiba.

O desenvolvimento de propostas, como o Projeto 127, pode ser uma das soluçóes para a realização de projetos com a comunidade do entorno, princi-

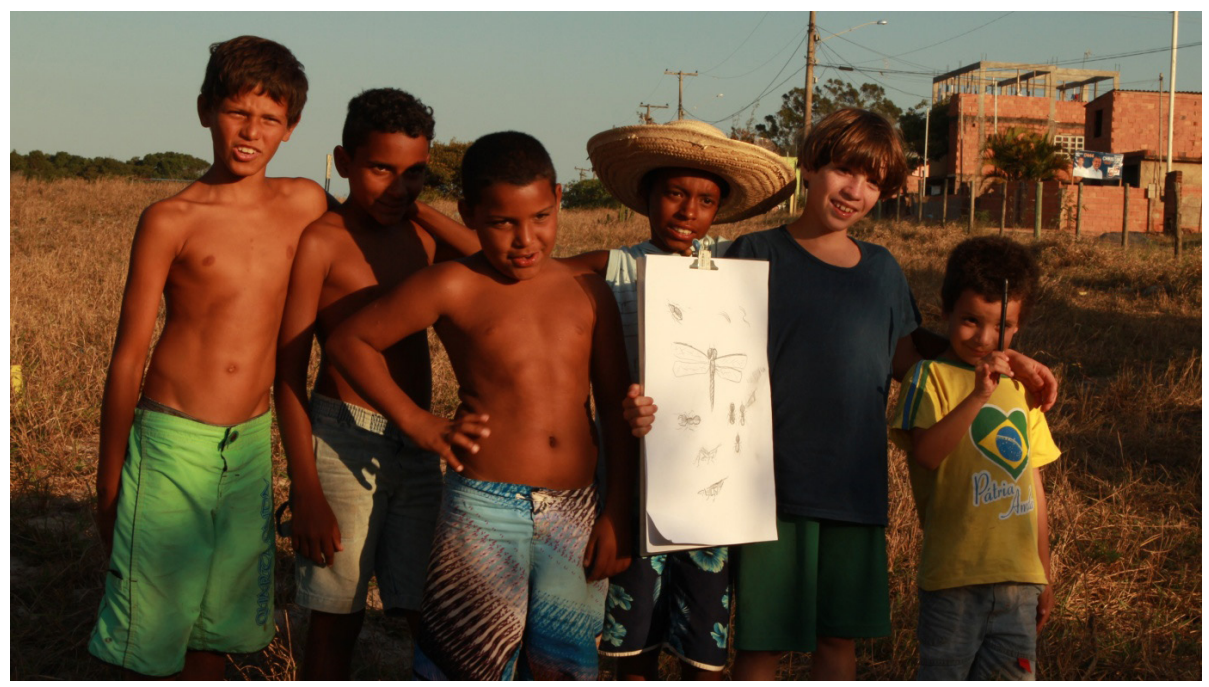

Figura 4

Personagens do filme Um Dia Novinho em Folha. 
palmente por ter sido criado por uma pessoa residente na própria comunidade. Valorizar ações como essa, criadas por um morador da área de entorno das UCs, apresenta-se como um dos caminhos para o desenvolvimento de um projeto local, sendo uma resposta às constantes críticas aos projetos sem diálogo, com fórmulas prontas e interesses diferenciados.

\section{Discussões finais: reflexões no universo criativo}

Este artigo propôs, a partir da prática e da reflexão de quatro documentários, contribuir para a compreensão da história ambiental local, vinculado ao Parque Nacional da Restinga de Jurubatiba. Buscamos promover uma reflexão em relação à implementação das UCs no Brasil e, principalmente, mostrar que a produção de filmes, realizados de maneira participativa e com base na escuta sensível, pode ser uma excelente forma de educação ambiental e construçáo de conhecimento.

Por ter sido construído de forma participativa entre os envolvidos, o CUCA torna-se um processo de aprendizado desde o seu início, já na delimitação do roteiro e do personagem a ser filmado, sendo uma rica experiência para os seus participantes.

Ao conhecer de perto a história de cada um desses personagens, os participantes do curso entram em contato com uma nova perspectiva de relacionamento entre humano e UC. Parafraseando Da-Rin (2004, p. 170), desta forma, os filmes produzidos não apresentam como única preocupação "o mundo representado, mas o próprio processo de representaçáo".

Apesar do processo, o resultado final (documentário) apresenta elementos que podem levantar discussões entre seus espectadores, já que o diálogo audiovisual destes personagens tende ainda a colaborar para a compreensão das diversas relações na UC.

Assim, deve-se realizar um esforço para modificar o pensamento vigente da educação ambiental como modificadora de indivíduos, intensificando a ideia de dicotomia entre sociedade e natureza.

Trazer a fala do morador para dentro da universidade gerou tensão e diversidade de entendimento: de um lado, os conservadores, e do outro, os sensíveis às causas socioambientais. $\mathrm{O}$ debate na universidade após a exibição dos filmes do projeto contribuiu para a formação dos profissionais das ciências ambientais.

\section{Notas}

1. Concebida em 1991 para incentivar investimentos culturais, a Lei Federal de Incentivo à Cultura (Lei no. 8.313/91), ou a Lei Rouanet, como também é conhecida, pode ser usada por empresas e pessoas físicas que desejam financiar projetos culturais. 
2. Projeto de pesquisa (vínculo institucional Pesquisas Ecológicas de Longa Duração - PELD Sítio 5), extensão (Cinema ambiental: educação e políticas públicas/Pró-Cultura 2015) e ensino (disciplina eletiva Documentário, Educação e Pesquisa oferecida nos cursos da UFRJ, campus de Macaé desde 2012).

3. A compra dos equipamentos e programas e o desenvolvimento do CUCA foi possível a partir de fomento do CNPq, por intermédio do Projeto de Pesquisas Ecológicas de Longa Duração (PELD-MCT/CNPq-N 59/2009-Proc. 558270/2009-3), da FAPERJ e da Fundação Educacional de Macaé (FUNEMAC), por meio do projeto Mudanças Climáticas Globais e o Funcionamento da Restinga de Jurubatiba: Estendendo a Pesquisa Científica à Sociedade Fluminense - FAPERJ/EXTPESQ (E-26/111.089/2010).

\section{Referências}

ANDRADE, E. Filhos de Jaú. Brasil: Amazon Picture, TV Cultura do Amazonas, Associação Brasileira de Emissoras Públicas, Educativas e Culturais (Abepec). 2009. Documentário (52 min.): Mini-DV, son., color.

BERNARD, H.R. Research methods in cultural anthropology. Newbury Park: Sage Publications, 1988.

BERNARDES, J.A.; FERREIRA, F.P.M. Sociedade e Natureza. In: CUNHA, S.B.; GUERRA, A.J.T. (Orgs.). A Questão Ambiental - Diferentes Abordagens. 6a ed. Rio de Janeiro: Bertrand Brasil, 2010. p. 17-42.

BRASIL. Portaria n. 54, de 1 de agosto de 2008. Aprova o Plano de Manejo do Parque Nacional da Restinga de Jurubatiba. Diário Oficial da República Federativa do Brasil, Brasília, DF.

BRUGGER, P. Educação ou adestramento ambiental. Florianópolis: Letras contemporâneas, 1994.

COSTA, R.N.; YU-MING, J.; SÁNCHEZ, C. O encontro do cinema com a educação ambiental crítica no Parque Nacional da Restinga de Jurubatiba. Anais do VIII EPEA Encontro Pesquisa em Educação Ambiental. Rio de Janeiro, 2015.

DA-RIN, S. O Espelho Partido, Tradição e Transformação do Documentário. Rio de Janeiro: Azougue Editorial, 2004.

FARJALLA, M.S.; BOZELLI, R.L.; LOUREIRO, C.F.B. Justiça Ambiental e Reconhecimento: o Caso do Parque Nacional da Restinga de Jurubatiba. Floresta $e$ Ambiente, v. 18, n. 4, p. 460-468, 2011. Disponível em: <http://www.floram.org/files/ v18n4/v18n4a12.pdf >. Acesso em 03 de dezembro de. 2015.

FISCHER, R.M.B. Docência, cinema e televisão: questóes sobre formação ética e estética. Revista Brasileira de Educação [online], v. 14, n. 40, p. 93-102, 2009. Disponível em: <http:// www.scielo.br/pdf/rbedu/v14n40/v14n40a08.pdf>. Acesso em 03 de dezembro de. 2015.

FUENTES, N.M.M. Territórios, saberes e imagens: um estudo sobre a percepção da população do entorno sobre o Parque Nacional da Restinga de Jurubatiba, Rio de Janeiro, Brasil. 2013. 162f. Dissertação (Mestrado) - Programa de Pós-Graduação em Ciências Ambientais e Conservação. Universidade Federal do Rio de Janeiro, Macaé, RJ. 
FUENTES, N.M.M.; COSTA, R.N.; ABREU, T.B.; RUTA, C. Construção de Oficinas Pedagógicas Através da Utilização de Ferramentas Audiovisuais com a População Humana do Entorno do Parque Nacional da Restinga de Jurubatiba In: VIII Encontro Nacional de Pesquisa em Educação em Ciências, 2011, Campinas. Anais... São Paulo, ABRAPEC, 2011.

GERHARDT, C. A invisibilização do outro nos discursos científicos sobre áreas naturais protegidas. Estudos Sociedade e Agricultura, Rio de Janeiro, v. 15, n. 2, p. 268-309, 2007. Disponível em: <http://r1.ufrrj.br/esa/V2/ojs/index.php/esa/article/viewFile/290/286>. Acesso em 03 de dezembro de. 2015.

GONÇALVES, M.A.T. O real imaginado: Etnografia, cinema e surrealismo em Jean Rouch. Rio de Janeiro: Topbooks, 2008.

GUIDO, L.F.E.; BRUZZO, C. Apontamentos sobre o cinema ambiental: a invenção de um gênero e a Educação Ambiental. Revista do Programa de Pós-Graduação em Educação Ambiental, v. 27, p. 57-68, jul./dez. 2011. Disponível em: <https://www.seer.furg.br/ remea/article/view/3249/1933>. Acesso em 03 de dezembro de. 2015.

GUTFREIND, C.F. O filme e a representação do real. Revista da Associação Nacional dos Programas de Pós-Graduação em Comunicação [online], v.2, n.12, 2006. Disponível em: $<$ http://www.compos.org.br/seer/index.php/e-compos/article/viewFile/90/90 >. Acesso em 03 de dezembro de. 2015.

INSTITUTO CHICO MENDES DE CONSERVAÇÃO DA BIODIVERSIDADE (ICMBIO). O que fazemos. 2014. Disponível em: <http://www.icmbio.gov.br/ portal/o-que-fazemos/visitacao/ucs-abertas-avisitacao/2593-parque-nacional-da-restingade-jurubatiba.html>. Acesso em 11 de maio de 2014.

KORNIS, M.A. História e Cinema: Um Debate Metodológico. Revista de Estudos Históricos (REH), v. 5, n. 10, p. 237-250, 1992. Disponível em: <http:// bibliotecadigital.fgv.br/ojs/index.php/reh/article/view/1940/1079>. Acesso em 03 de dezembro de. 2015.

LEFF, E. Epistemologia Ambiental. 5a ed. São Paulo: Cortez, 2010.

LINS, C.; MESQUITA, C. Filmar o Real: Sobre o Documentário Brasileiro Contemporâneo. Rio de Janeiro: Jorge Zahar Editora, 2008.

LOUREIRO, C.F.B. Complexidade e Dialética: Contribuiçōes à Práxis Política e Emancipatória em Educação Ambiental. Educação \& Sociedade, Campinas, v.27, n.94, p. 131-152, 2006. Disponível em: <http://www.scielo.br/scielo.php?script=sci $\underline{\text { arttext } \& \text { pid }=S 0101-73302005000400020}>$. Acesso em 03 de dezembro de. 2015.

LOUREIRO, C.F.B.; CUNHA, C.C. Educação Ambiental e Gestão Participativa de Unidades de Conservação: Elementos para se Pensar a Sustentabilidade Democrática. Ambiente \& Sociedade, Campinas, v. 11, n. 2, p. 237-253, 2008. Disponível em: < http:// www.scielo.br/scielo.php?script $=$ sci arttext $\&$ pid $=\$ 1414-753 X 2008000200003>$. Acesso em 03 de dezembro de. 2015.

LOUREIRO, C.F.B.; LAYRARGUES, P.P.; CASTRO, R.S. (Orgs.). Educação Ambiental: Repensando o Espaço da Cidadania. São Paulo: Cortez, 2002. 
MINISTÉRIO PÚBLICO FEDERAL (MPF). Quinze pescadores trabalham há mais de 12 anos em Carapebus. 2010. Disponível em: <http://noticias.pgr.mpf.gov.br/noticias/ noticias-do-site/copy of meio-ambiente-e-patrimonio-cultural/mpf-rj-regulariza-pescaem-lagoa-do-parque-de-jurubatiba >. Acesso em 11 de maio de 2014.

MORAN, J.M. Ensino e Aprendizagem Inovadores com Tecnologias. Informática na Educação, v. 3, n. 1, p. 137-144, 2000. Disponível em: <http://seer.ufrgs.br/index.php/ InfEducTeoriaPratica/article/view/6474/3862>. Acesso em 03 de dezembro de. 2015.

NICHOLS, B. Introdução ao Documentário. 3a ed. Campinas: Papirus, 2005.

OLIVEIRA, B.J. Cinema e imaginário científico. História, Ciências, Saúde-Manguinhos, Rio de Janeiro, v. 13, (suplemento), p. 133-50, out. 2006. Disponível em: <http://www. scielo.br/scielo.php?script=sci arttext \&pid=S0104-59702006000500009 >. Acesso em 03 de dezembro de. 2015.

ROCHA, C.F.D.; ESTEVES, F.A. \& SCARANO, F.R. Pesquisas de Longa Duração na Restinga de Jurubatiba: Ecologia, História Natural e Conservação. São Carlos: Editora RiMa, 2004.

ROSA, P.R.S. O Uso dos Recursos Audiovisuais e o Ensino de Ciências. Caderno Catarinense de Ensino de Física, v. 17, n. 1, p. 33-49, 2000. Disponível em: <https://periodicos.ufsc.br/ index.php/fisica/article/view/6784/6249>. Acesso em 03 de dezembro de. 2015.

SANTOS, M.C. Contribuição à Gestão das Lagoas Costeiras: Conhecimento Tradicional, Técnico e Científico Associado ao Manejo dos Recursos Naturais da Lagoa de Carapebus, Parque Nacional da Restinga de Jurubatiba - RJ. 2008. 135f. Dissertação (Mestrado) Centro Federal de Educação Tecnológica Celso Suckow da Fonseca, Campos dos Goytacazes.

SPENCER, C. Dança do Tempo. Rio de Janeiro, 2011. Documentário (22 min.): Mini-DV, son., color.

SPORKENS, B. Expedição Floriano. Brasil: Ibama, 2004. Documentário (55 min.): Mini-DV, son., color.

VAINER, A.G. Território, Meio Ambiente e Conflitos: Estudo de Caso do Parque Nacional da Restinga de Jurubatiba. 2010. 213f. Dissertação (Mestrado) - Universidade Federal Fluminense, Niterói.

XAVIER, I. A experiência do cinema - antologia. Rio de Janeiro: Ediçôes Graal: Embrafilmes, 1983.

Recebido em 29 de fevereiro de 2016.

Aprovado em 04 de abril de 2016. 